\title{
Graphitic carbon nanostructures from cellulose
}

\author{
M. Sevilla * , A. B. Fuertes \\ Departamento de Química de Materiales \\ Instituto Nacional del Carbón (CSIC), P. O. Box 73, 33080-Oviedo, Spain \\ *Corresponding author. Fax: +34 985297662 \\ E-mail address: martasev@,incar.csic.es
}

\begin{abstract}
Graphitic carbon nanostructures have been synthesized from cellulose via a simple methodology that essentially consists of the steps: i) hydrothermal treatment of cellulose at $250^{\circ} \mathrm{C}$ and ii) impregnation of the carbonaceous product with a nickel salt followed by thermal treatment at $900^{\circ} \mathrm{C}$. The formation of graphitic carbon nanostructures seems to occur by a dissolution-precipitation mechanism in which amorphous carbon is dissolved in the catalyst nanoparticles and then precipitated as graphitic carbon around the catalyst particles. The subsequent removal of the nickel nanoparticles and amorphous carbon by oxidative treatment leads to graphitic nanostructures with a coil morphology. This material exhibits a high degree of crystallinity and large and accessible surface area.
\end{abstract}




\section{Introduction}

Carbon nanostructures are receiving widespread attention due to their attractive chemical and physical properties (i.e. chemical resistance, mechanical strength, good thermal and electrical conductivity and high external surface area), which make them suitable for applications in areas such as electron field emission, storage and production of energy, hydrogen storage, nanocomposites, catalyst support or drug delivery [1-4]. These nanostructures can be synthesized in a wide variety of morphologies, such as tubes, fibers, onions, horns, capsules, ribbons or coils [2, 3, 5-7]. This type of materials is normally synthesized under harsh conditions $\left(\mathrm{T}>5000^{\circ} \mathrm{C}\right)$, by means of a laser, plasma or arch discharge $[5,8,9]$. However, the use of a catalyst may lead to a softening of the synthesis conditions and a reduction of the temperature at values as low as $600^{\circ} \mathrm{C}[10]$. The chemicals that act as catalyst in the graphitization process are transition metals, such as $\mathrm{V}, \mathrm{Zr}, \mathrm{Pt}, \mathrm{Ti}, \mathrm{Al}, \mathrm{Mn}, \mathrm{Fe}, \mathrm{Co}$, or Ni $[11,12]$, or metallic compounds, such as $\mathrm{Cr}_{2} \mathrm{O}_{3}, \mathrm{MnO}_{2}, \mathrm{MnO}_{3}$ or $\mathrm{Fe}_{3} \mathrm{O}_{4}[12,13]$. Among these, Fe, Ni and Co have been found to be particularly effective as catalysts in the production of graphitic structures at temperatures $<1000^{\circ} \mathrm{C}[14,15]$. This catalytic process makes it possible to transform both the graphitizing and non-graphitizing precursors into graphitic carbon, thereby broadening its applicability to a wider range of substances. Of course, the use of cheap precursors would reduce considerably the cost of the process. Among the possible carbon precursors, saccharides are widely available and low-priced. However, cellulose is the cheapest and most abundant of all the naturally occurring organic compounds and, what is more, it is renewable. Although it is commonly used as precursor for activated carbons, to the best of our knowledge, it has only once been used to prepare graphitic carbon nanostructures [16]. In this case, the graphitic carbon nanostructures were synthesized at a very high temperature (laser pyrolysis), $2250^{\circ} \mathrm{C}$, 
which increases the cost and complexity of the process. Here we investigate the use of cellulose as a starting point for fabricating graphitic nanostructures. The synthesis strategy involves two basic steps: a) the hydrothermal carbonization of cellulose at a temperature of around $250^{\circ} \mathrm{C}$ to obtain an intermediate highly functionalized carbonaceous solid, here denoted as hydrochar, and b) the impregnation of the hydrochar with a nickel salt and its carbonization up to $900^{\circ} \mathrm{C}$. The nickel $\left(\mathrm{Ni}^{2+}\right)$ which is incorporated into the hydrochar is converted into metallic nickel nanoparticles during carbonization. These nanoparticles act as a catalyst for the conversion of a fraction of the amorphous carbon formed into graphitic carbon. Two mechanisms have been proposed to explain the process of catalytic graphitization [12]: a) the dissolutionprecipitation mechanism, whereby amorphous carbon first dissolves into the metal catalyst, which then precipitates as graphitic carbon and b) the formation-decomposition of carbide intermediates, whereby the carbon forms a carbide with the metal, which then decomposes at a certain temperature, leaving behind graphitic carbon. In the present work, in order to clarify the mechanism of catalytic graphitization of cellulosic products, we paid special attention to the chemical transformations occurring during the heat treatment. Accordingly, the nickel impregnated hydrochar was subjected to heat treatments at different temperatures in the $300-900^{\circ} \mathrm{C}$ range and characterized by X-ray diffraction, thermogravimetric analysis, X-ray photoelectron spectroscopy and transmission electron microscopy.

\section{Experimental}

\subsection{Preparation of materials}

A cellulose-derived hydrochar material was used as carbon precursor in the synthesis of the graphitic carbon nanostructures. This material was obtained through the hydrothermal carbonization of cellulose $\left(320 \mathrm{~g} \cdot \mathrm{L}^{-1}\right)$ at $250^{\circ} \mathrm{C}$ for $2 \mathrm{~h}$ [17]. After that, it 
was subjected to the following processes: a) impregnation with a solution of nickel nitrate $\left(\mathrm{Ni}\left(\mathrm{NO}_{3}\right)_{2} \cdot 6 \mathrm{H}_{2} \mathrm{O}\right)$ in ethanol $\left(\sim 3 \mathrm{mmol} \mathrm{metal} \cdot \mathrm{g}^{-1} \mathrm{C}\right)$, b) heat-treatment under $\mathrm{N}_{2}$ at $900^{\circ} \mathrm{C}\left(3^{\circ} \mathrm{C} \cdot \mathrm{min}^{-1}\right)$ for $\left.3 \mathrm{~h}, \mathrm{c}\right)$ oxidative treatment (under reflux for $2 \mathrm{~h}$ ) of the solid product in an acid solution of potassium permanganate (molar composition of $\left.\mathrm{H}_{2} \mathrm{O} / \mathrm{H}_{2} \mathrm{SO}_{4} / \mathrm{KMnO}_{4}=1: 0.02: 0.006\right)$. This last step allows the metal catalyst nanoparticles and the amorphous carbon to be removed. Finally the insoluble solid product (graphitic carbon nanoparticles) is separated by centrifugation, washed with $\mathrm{HCl}(10 \mathrm{wt} \%)$ in order to remove the $\mathrm{MnO}_{2}$ formed, rinsed with abundant distilled water and oven-dried at $120^{\circ} \mathrm{C}$ for $2 \mathrm{~h}$.

\subsection{Characterization}

Scanning electron microscopy (SEM) microphotographs were obtained with a Zeiss DSM 942 microscope. Transmission electron microscopy (TEM) images were taken on a JEOL (JEM-2000 EX II) microscope operating at $160 \mathrm{kV}$, while the selected area electron diffraction (SAED) patterns of the graphitic carbon nanostructures were recorded on a JEOL (JEM-2000 FX) microscope operating at $200 \mathrm{kV}$. High-resolution transmission electron (HRTEM) micrographs were obtained on a JEOL (JEM-3000F) microscope operating at $300 \mathrm{kV}$. X-ray diffraction (XRD) patterns were recorded on a Siemens D5000 instrument operating at $40 \mathrm{kV}$ and $20 \mathrm{~mA}$, using $\mathrm{Cu} \mathrm{K} \alpha$ radiation $(\lambda=$ $0.15406 \mathrm{~nm}$ ). The plane spacing, $\mathrm{d}_{002}$, was calculated by applying Bragg's law to the (002) diffraction peak, whereas the crystallite sizes along the basal plane, $\mathrm{L}_{\mathrm{a}}$, and perpendicular to the basal plane, $\mathrm{L}_{\mathrm{c}}$, were deduced by means of Scherrer's equation. The Raman spectra were recorded on a Horiva (LabRam HR-800) spectrometer. The source of radiation was a laser operating at a wavelength of $514 \mathrm{~nm}$ and a power of $25 \mathrm{~mW}$. Xray photoelectron spectroscopy (XPS) was carried out by means of a Specs spectrometer, using $\mathrm{MgK} \alpha(1253.6 \mathrm{eV})$ radiation from a double anode at $50 \mathrm{w}$. The 
thermogravimetric experiments were performed in a C.I. Electronics analyser. Adsorption measurements of the graphitic carbon nanostructures were obtained using a Micromeritics ASAP 2020 volumetric physisorption system. The BET surface area was deduced from an isotherm analysis in the relative pressure range of $0.04-0.20$. The total pore volume was calculated from the amount adsorbed at a relative pressure of 0.99 . The external surface area $\left(\mathrm{S}_{\mathrm{ext}}\right)$ was estimated by means of the $\alpha_{\mathrm{s}}$-plot method and a non-graphitized carbon black was used as reference [18].

\section{Results and Discussion}

\subsection{Catalytic graphitization of cellulosic hydrochar}

A nickel impregnated hydrochar was subjected to heat treatment under nitrogen at different temperatures in the $300-900^{\circ} \mathrm{C}$ range and the XRD patterns were recorded. These are depicted in Figure 1. When the nickel impregnated hydrochar is heat-treated at $300^{\circ} \mathrm{C}$, $\mathrm{NiO}$ nanoparticles appear in the carbonaceous matrix as a consequence of the decomposition of nickel nitrate, as evidenced by the appearance of X-ray diffraction peaks at $2 \theta \sim 36^{\circ}, 43^{\circ}$ and $62^{\circ}$ which can be assigned respectively to the (111), (200) and (220) planes of the face-centered cubic structure of the NiO. For higher temperatures, the $\mathrm{NiO}$ nanoparticles are reduced by the carbon and consequently the XRD patterns only contain the peaks characteristic of the face-centered cubic structure phase of Ni (i.e. (111), (200) and (220) at $2 \theta \sim 44^{\circ}, 52^{\circ}$ and $76^{\circ}$ respectively). These peaks become more intense as the carbonization temperature increases. This is due to the growth of the nickel nanoparticles, whose size increases from $4 \mathrm{~nm}\left(300^{\circ} \mathrm{C}\right)$ to $\sim 17 \mathrm{~nm}\left(900^{\circ} \mathrm{C}\right)$, as was deduced by applying the Scherrer equation to the (111) peak of Ni. These transformations were also examined by thermogravimetric analysis of the nickel-impregnated hydrochar sample. Figure 2 shows the sample weight changes (weight loss and weight loss rate) that take place when the sample is heat-treated under nitrogen atmosphere. The continued 
decrease in weight with the increase in temperature is due to the pyrolysis of the hydrochar and the decomposition of the nickel (II) nitrate hexahydrate into different nickel compounds. Three peaks can be identified in the weight loss rate graph. The peak at $\sim 240^{\circ} \mathrm{C}$ may be attributed to the partial decomposition of the nickel (II) nitrate hexahydrate as a previous step to its complete decomposition into NiO. Several studies have shown that the decomposition of nickel (II) nitrate hexahydrate is a complex process since the nickel decomposes before the removal of all the water of crystallization, into intermediate compounds, the exact composition of which has not yet been established [19-21]. The narrow peak at around $267^{\circ} \mathrm{C}$ corresponds to the decomposition of this intermediate compound into $\mathrm{NiO}$, as supported by $\mathrm{XRD}$ analysis (see Figure 1), and the broad peak at $\sim 385^{\circ} \mathrm{C}$ is due to two superimposed processes: i) the reduction of $\mathrm{NiO}$ to $\mathrm{Ni}$ due to a redox reaction with carbon, as previously shown by XRD (see Figure 1) and ii) the carbonization of the hydrochar material (see TGA in ref. [17]). This TGA pattern differs from that obtained for the nickel nitrate-impregnated charcoal, where the reduction of $\mathrm{NiO}$ to $\mathrm{Ni}$ by means of carbon occurs at a higher temperature than in this case [22], which suggests that the hydrochar has a greater power of reduction.

The XRD patterns displayed in Figure 1 also provide information about the structural changes in the carbonaceous matrix. Thus, for tempertatures $<700^{\circ} \mathrm{C}$ no peak associated to the graphitic framework is detected, indicating that the carbonaceous matrix is amorphous. However, for $\mathrm{T} \geq 700^{\circ} \mathrm{C}$ a sharp peak appears at $2 \theta \sim 26^{\circ}$, which is attributed to the (002) reflection of the graphitic framework. This peak is superimposed on a broad band corresponding to amorphous carbon (see zoom in Figure 1). For $\mathrm{T} \geq 730^{\circ} \mathrm{C}$, this reflection is more intense and is accompanied by small peaks at $2 \theta \sim 43^{\circ}$ and $55^{\circ}$, which are associated to (01) and (004) reflections of the graphitic framework. These peaks are almost completely hidden by the intense reflections adscribed to nickel nanoparticles. 
These results show that the onset of catalytic graphitization takes place at temperatures $\geq$ $700^{\circ} \mathrm{C}$, which is in agreement with previous observations for other saccharide-based hydrochar materials [23]. As the temperature rises from 700 to $900^{\circ} \mathrm{C}$, the (002) peak becomes more intense, denoting an increase in the (graphitic carbon)/(amorphous carbon) ratio. However, the structural characteristics of the materials $\left(\mathrm{d}_{002}\right.$ and $\left.\mathrm{L}_{\mathrm{c}}\right)$, hardly change at all as the temperature increases $\left(\mathrm{d}_{002} \sim 0.342-0.343 \mathrm{~nm}\right.$ and $\left.\mathrm{L}_{\mathrm{c}} \sim 7.0-7.6 \mathrm{~nm}\right)$. These results suggest that the increase in temperature does not have a significant influence on the degree of structural order of the graphitic carbon, but it does influence the amount of graphitic carbon generated, as previously observed for other carbon precursors [23, 24]. The variation of the graphitic/amorphous carbon ratio with the carbonization temperature was exammined by means of XPS spectroscopy (Figure 3). It was found that for the sample heat-treated at $730^{\circ} \mathrm{C}$ the ratio between the area of the peak corresponding to graphitic carbon, i.e. $\mathrm{C}=\mathrm{C}$ groups $\left(\mathrm{E}_{\mathrm{B}}=284.4 \mathrm{eV}\right)$ and that of the peak attributed to amorphous carbon, i.e. $\mathrm{C}-\mathrm{C} / \mathrm{CH}_{\mathrm{x}}$ groups $\left(\mathrm{E}_{\mathrm{B}}=285.1 \mathrm{eV}\right)$ is 0.434 , whereas for the sample heat-treated at $900^{\circ} \mathrm{C}$ it is 0.756 , which indicates an increase in the amount of graphitic carbon as the temperature rises. The presence of oxygen groups remaining in the graphitized materials is revealed by the peaks at around 287.2 and $289.2 \mathrm{eV}$, which are attributed to carbonyl groups $(>\mathrm{C}=\mathrm{O})$ and carboxylic groups, esters or lactones $(-\mathrm{COOR})$ respectively [25].

The XRD patterns and the TEM images of the carbonized samples reveal that they contain both amorphous and graphitic carbon. It suggests that the mechanism of catalytic graphitization is dissolution-precipitation. Thus, in the XRD spectra (see Figure 1) only nickel metallic nanoparticles are identified in the samples heat-treated at different temperatures. No nickel carbide has been detected at any temperature, ruling out the carbide formation-decomposition mechanism. On the other hand, the TEM images in 
Figure 4 show that graphitic carbon is located around the nickel nanoparticles or in their vicinity whereas the carbon far away from the nickel nanoparticles remains amorphous. This is in accordance with the dissolution of amorphous carbon in the metallic nanoparticles and its precipitation as graphitic carbon, which then remains in the vicinity of, or not far away from, the catalyst nanoparticles $[12,26]$. The morphology of the graphitic structures is the result of the movement of the catalyst nanoparticles throughout the amorphous carbon matrix, leaving behind a trail of graphitic carbon.

\subsection{Structural characteristics of the graphitized carbons}

As a consequence of the catalytic graphitization process, graphitic carbon nanostructures appear immersed in a matrix of amorphous carbon, together with metallic nanoparticles (Figure 4). The metallic nanoparticles, as well as the amorphous carbon, can be selectively removed by means of liquid-phase oxidation with an acid solution of permanganate potassium. This is demonstrated by the TEM images and XRD patterns obtained after the oxidative treatment (see Figure $5 \mathrm{~b}$ and $5 \mathrm{c}$ ), where no Ni nanoparticles or amorphous carbon can be identified. The yield of this oxidative treatment is $34 \%$ (i. e. $34 \mathrm{~g}$ of GCNs are extracted per $100 \mathrm{~g}$ of graphitized material) whereas the yield of the overall process is around $8 \%$ (i.e. $8 \mathrm{~g} \mathrm{GCNs} / 100 \mathrm{~g}$ cellulose). A diagram of the overall synthesis process is presented in Figure 6. The graphitic nanocarbons consist of nanoparticles with a size $<200 \mathrm{~nm}$, as evidenced by the SEM image shown in Figure 5a. TEM inspection of these nanoparticles reveals that they have a nanocoil morphology (see Figure 5b). Well-defined (002) lattice fringes are observed in the high-resolution transmission electronic microscopy images (see inset Figure 5b), which evidences the high degree of crystallinity of the graphitic carbon nanostructures. This is confirmed by the selected area electron diffraction pattern (Figure 5c, inset), Xray diffraction analysis (Figure 5c) and Raman spectroscopy (Figure 5d). Thus, the 
XRD pattern for these nanostructures contains intense peaks at $2 \theta \sim 26^{\circ}, 43^{\circ}, 54^{\circ}$ and $78^{\circ}$, which correspond to the (002), (10), (004) and (110) diffractions of the graphitic framework, respectively. The plane spacing, $\mathrm{d}_{002}$, has a value of $0.341 \mathrm{~nm}$ whereas the crystallite sizes along the basal plane, $\mathrm{L}_{\mathrm{a}}$, and perpendicular to the basal plane, $\mathrm{L}_{\mathrm{c}}$, have values of 16 and $9.8 \mathrm{~nm}$, respectively. The first-order Raman spectrum of the carbon nanostructures displayed in Figure 5d reveals intense and narrow D and G bands at 1341 and $1570 \mathrm{~cm}^{-1}$. In addition, the $\mathrm{G}^{\prime}$ band, which corresponds also to the disordered induced phase, is observed at around $1610 \mathrm{~cm}^{-1}$. By fitting this band, an $\mathrm{I}_{\mathrm{D}} / \mathrm{I}_{\mathrm{G}}$ ratio equal to 1.02 was obtained, indicating a high proportion of edge planes and a distortion of the graphitic planes in the carbon nanostructures. The graphene layers around the catalyst nanoparticles follow their shape. It is also worth noting that the nanostructures prepared by catalytic graphitization possess higher values of $L_{a}$ than $L_{c}[14,23,27]$, which suggests that growth of the nanostructures takes place in the direction of the basal plane rather than perpendicular to the basal plane. These results prove that the carbon nanostructures have a high graphitic order. Moreover, the analysis of the textural properties of these carbon nanostructures by means of the $\mathrm{N}_{2}$ sorption isotherm shows that they do not contain framework-confined pores and that they have quite a large external surface area, of aprox. $114 \mathrm{~m}^{2} \cdot \mathrm{g}^{-1}$ (see Figure 7). This external surface area matches the specific surface area, as the adsorption only takes place on the external surface of the nanoparticles.

\section{Conclusions}

In summary, we have proved that the carbonaceous products obtained by the hydrothermal treatment of cellulose constitute an excellent precursor for the preparation of graphitic carbon nanostructures. The main advantages of this precursor are that: i) it is obtained from the cheapest and most abundant of all the naturally occurring organic 
compounds, ii) it is synthesized by means of a "green" process (only water is involved as solvent) and iii) it possesses a high concentration of oxygen functionalities, which favours the impregnation and dispersion of the catalyst. With the aid of nickel nanoparticles that act as catalyst, this material can be transformed, via a dissolutionprecipitation mechanism, at moderate temperatures $\left(900^{\circ} \mathrm{C}\right)$ into graphitic nanostructures with a coil morphology and a high degree of crystallinity, as evidenced by HRTEM/SAED, XRD and Raman spectroscopy. These curved structures are the result of the growth of graphene layers around the catalyst nanoparticles, following their shape. Finally, these nanostructures possess, in combination with the high crystallinity, an accessible surface area, which makes them ideal candidates for use in electrochemical applications as fuel cell catalytic supports or as anodes in Li-ion batteries.

Acknowledgments. The financial support for this research work provided by the Spanish MCyT (MAT2008-00407) is gratefully acknowledged. M. S. acknowledges the assistance of the Spanish MCyT for the award of a Postdoctoral Mobility contract.

\section{References}

[1] E.T. Thostenson, Z. Ren, T.W. Chou, Compos. Sci. Technol. 61 (2001) 1899.

[2] P. Serp, P.M. Corrias, P. Kalck, Appl. Catal. A 253 (2003) 337.

[3] Y. Liu, Z. Shen, Carbon 43 (2005) 1574.

[4] N. Venkatesan, J. Yoshimitsu, Y. Ito, N. Shibata, K. Takada, Biomaterials 26 (2005) 7154.

[5] Charinpanitkul, T.; Tanthapanichakoon, W.; Sano, N. Curr. Appl. Phys. 9 (2009) 629.

[6] D. Ugarte, Carbon 33 (1995) 989. 
[7] K. Wakabayashi, M. Fujita, H. Ajiki, M. Sigrist. Phys Rev B 59 (1999) 8271.

[8] T. Guo, P. Nikolaev, A. Thess, D.T. Colbert, R.E. Smalley, Chem. Phys. Lett. 243 (1995) 49.

[9] C.K. Tan, K.P. Loh, J.T.L. Thong, C.H. Sow, H. Zhang, Diam. Relat. Mater. 14 (2005) 902.

[10] O. P. Krivoruchko, N. I. Maksimova, V.I. Zaikovskii, A. N. Salanov. Carbon 38 (2000) 1075-1082.

[11] H. Marsh, A.P. Warburton. J. Appl. Chem. 20 (1970) 133.

[12] A. Oya, H. Marsh.. J. Mater. Sci. 17 (1982) 309.

[13] I. Mochida, R. Ohtsubo, K. Takeshita, H. Marsh. Carbon 18 (1980) 117.

[14] M. Sevilla, C. Sanchís, T. Valdés-Solís, E. Morallón, A. B. Fuertes. J. Phys. Chem. C 111 (2007) 9749.

[15] A. Oya, S. Yoshida, J. Alcañiz-Monje, A. Linares-Solano. Carbon 33 (1995) 1085.

[16] A.M. Herring, J.T. McKinnon, B.D. McCloskey, J. Filley, K.W. Gneshin, R.A. Pavelka, H-J. Kleebe, D.J. Aldrich. J. Am. Chem. Soc. 125 (2003) 9916.

[17] M. Sevilla, A.B. Fuertes. Carbon 47 (2009) 2281.

[18] M. Kruk, K.P. Jaroniec, J. Gadkaree. Colloid. Interface Sci. 192 (1997) 250.

[19] W.M. Keely, H.W. Maynor. J. Chem. Eng. Data 8 (1963) 297.

[20] W. Brockner, C. Ehrhardt, M. Gjikaj. Thermochim. Acta 456 (2007) 64.

[21] J. Estellé, P. Salagre, Y. Cesteros, M. Serra, F. Medina, J.E. Sueiras. Solid State Ionics $156(2003) 233$.

[22] L.M. Gandia, M. Montes. J. Catal. 145 (1994) 276.

[23] M. Sevilla, A.B. Fuertes. Mater. Chem. Phys. 113 (2009) 208.

[24] M. Sevilla, PhD Thesis, University of Oviedo, 2008. 
[25] T.I.T. Okpalugo, P. Papakonstantinou, H. Murphy, J. McLaughlin, N.M.D. Brown. Carbon 43 (2005) 153.

[26] H. Marsh, D. Crawford, D.W. Taylor. Carbon 21 (1983) 81.

[27] M. Sevilla, C. Salinas Martínez-de Lecea, T. Valdés-Solís, E. Morallón, A. B. Fuertes. Phys. Chem. Chem. Phys. 10 (2008) 1433. 


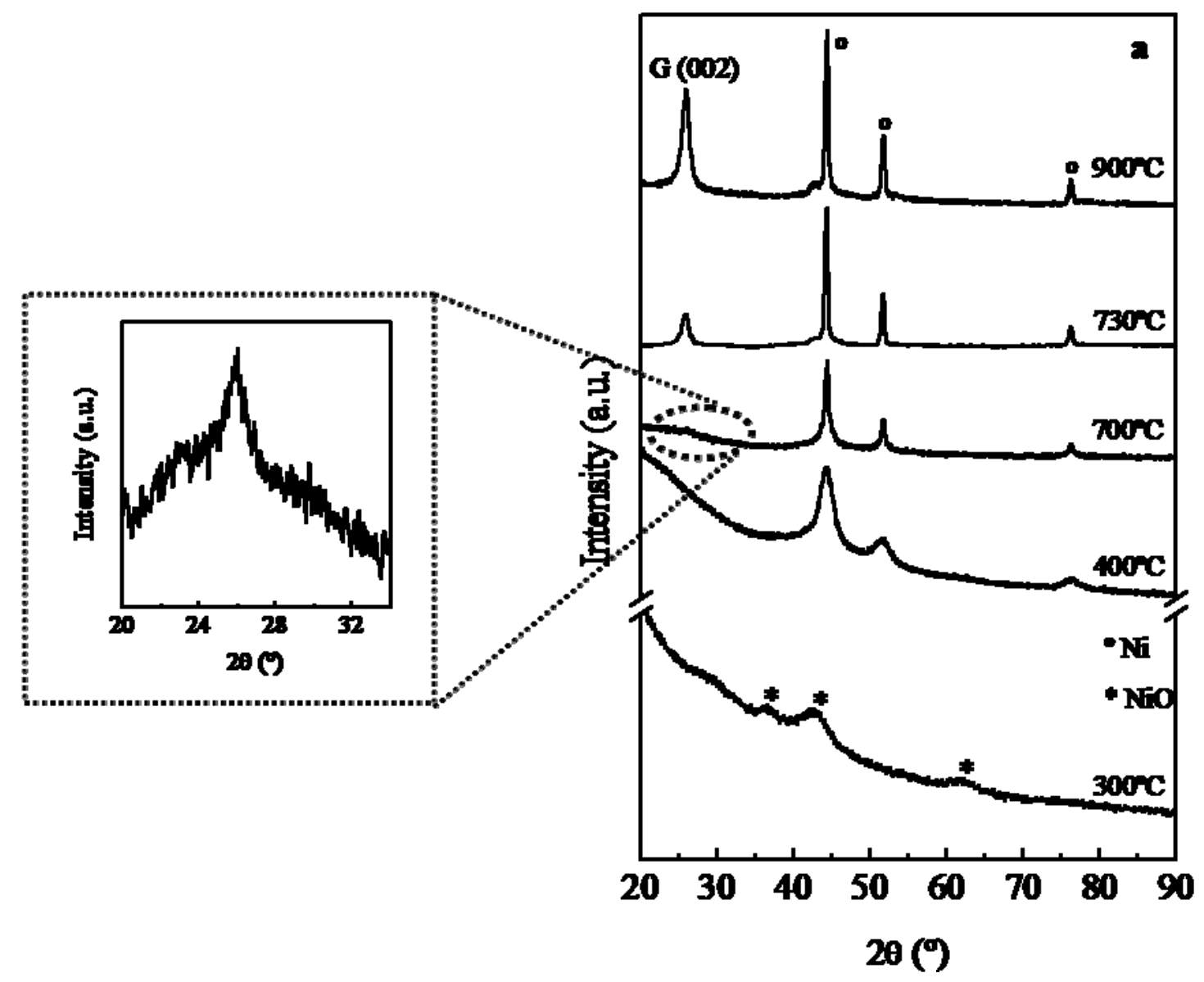

Figure 1. XRD patterns of the nickel impregnated hydrochar carbonized at different temperatures. 


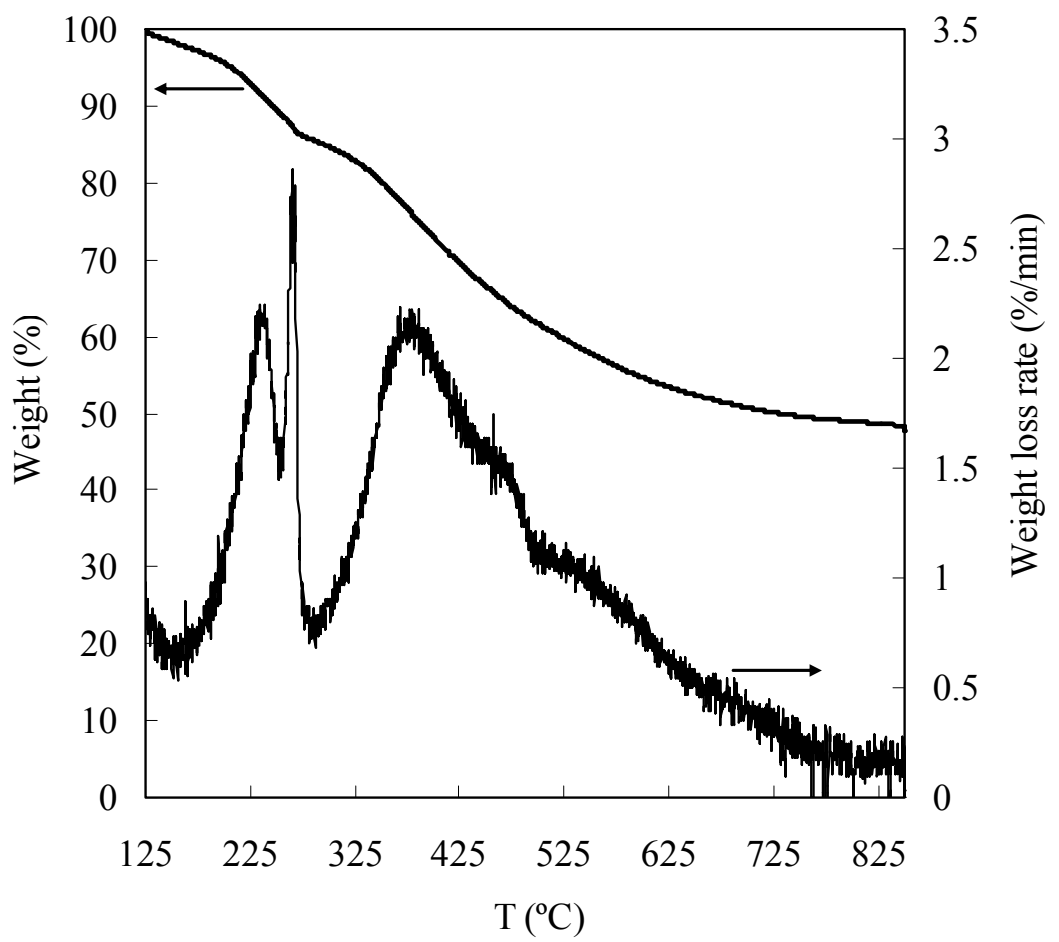

Figure 2. TGA of the nickel impregnated hydrochar $\left(\mathrm{N}_{2}\right.$ atmosphere, $5^{\circ} \mathrm{C} / \mathrm{min}-850^{\circ} \mathrm{C}$ 1h): variation of sample weight and weight loss rate with temperature. 

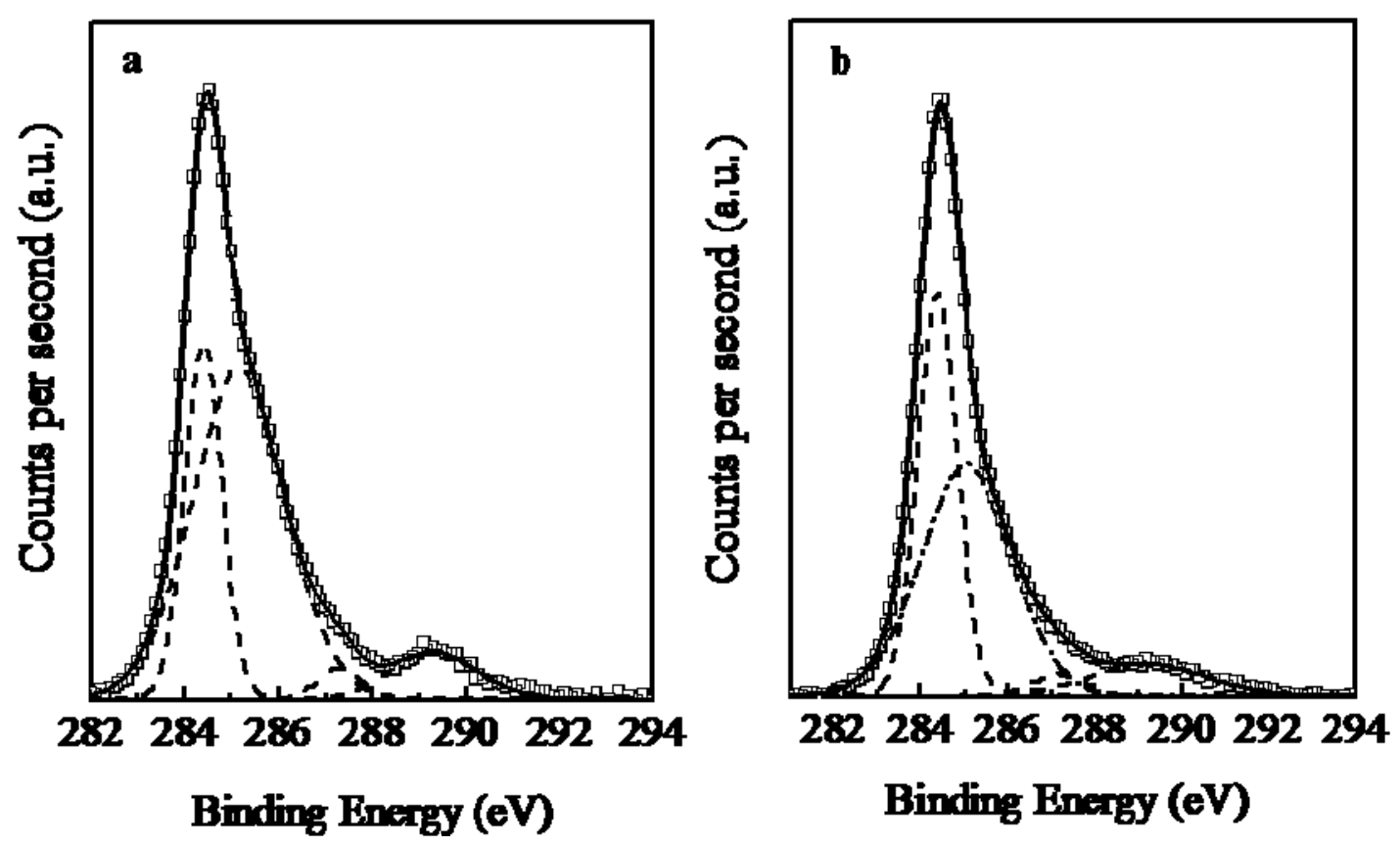

Figure 3. XPS spectra of the Ni-impregnated hydrochar samples heat-treated at $730^{\circ} \mathrm{C}$ (a) and $900^{\circ} \mathrm{C}(\mathrm{b})$. 

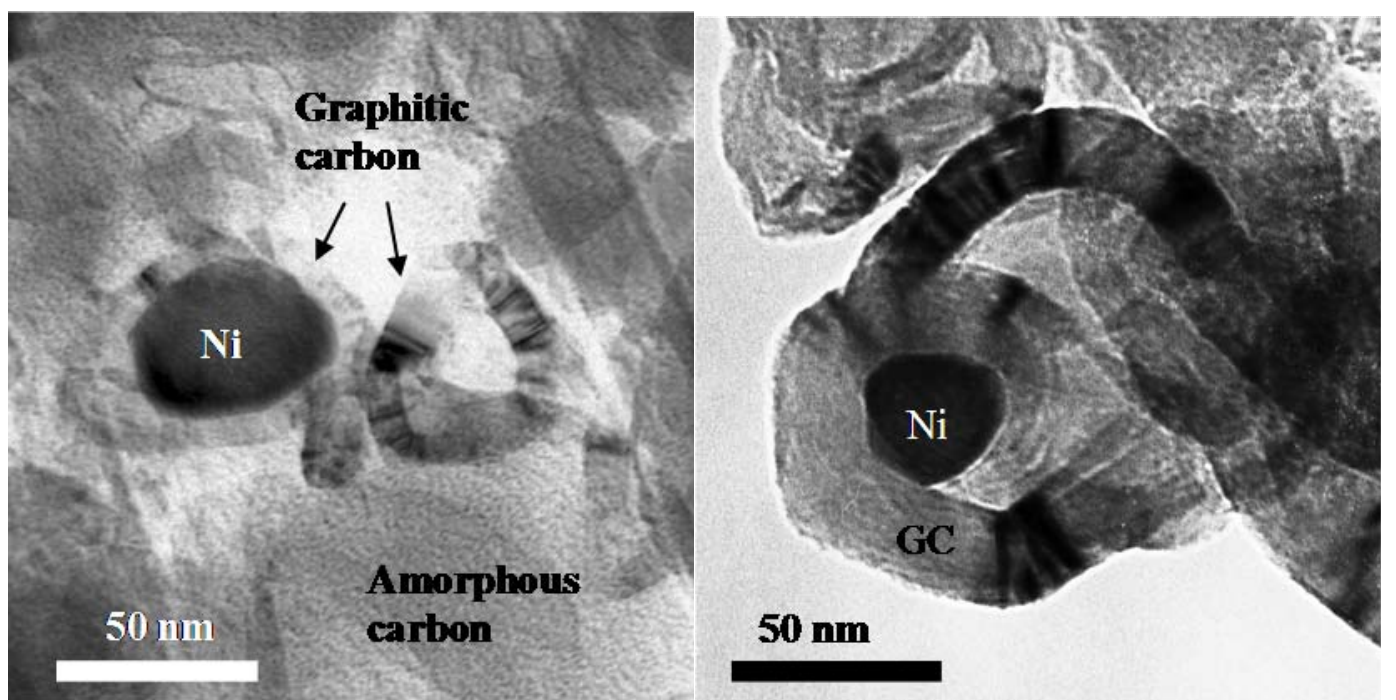

Figure 4. TEM images of the nickel-impregnated sample heat-treated at $900^{\circ} \mathrm{C}(\mathrm{GC}=$ graphitic carbon, $\mathrm{Ni}=$ nickel nanoparticles). 

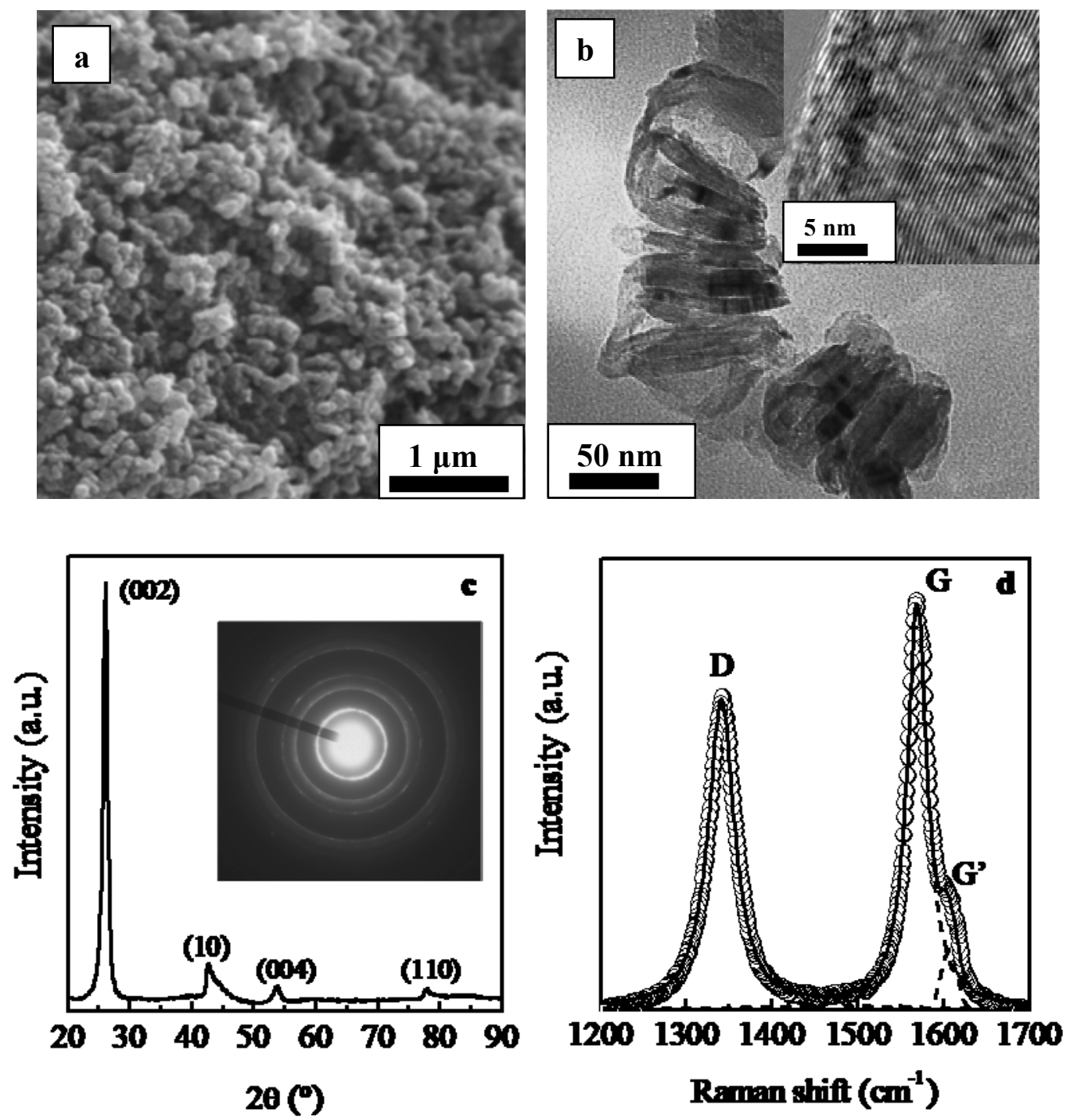

Figure 5. Structural characteristics of the graphitic carbon nanostructures obtained from the cellulose-derived hydrochar sample. (a) SEM microphotograph, (b) TEM image (Inset: HRTEM image), (c) XRD pattern (Inset: Selected Area Electron Diffraction pattern) and (d) First-order Raman spectrum. 
Cellulose
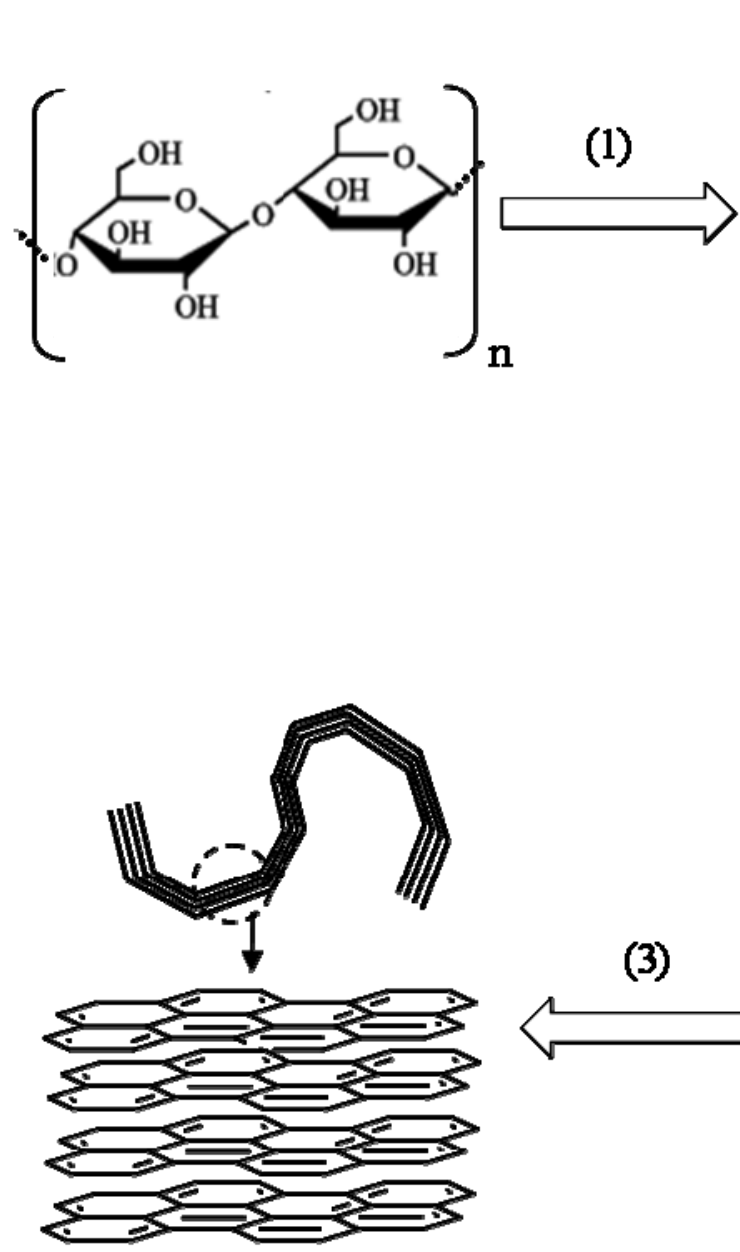

Graphitic carbon nanostructures

(3)
Hydrochar
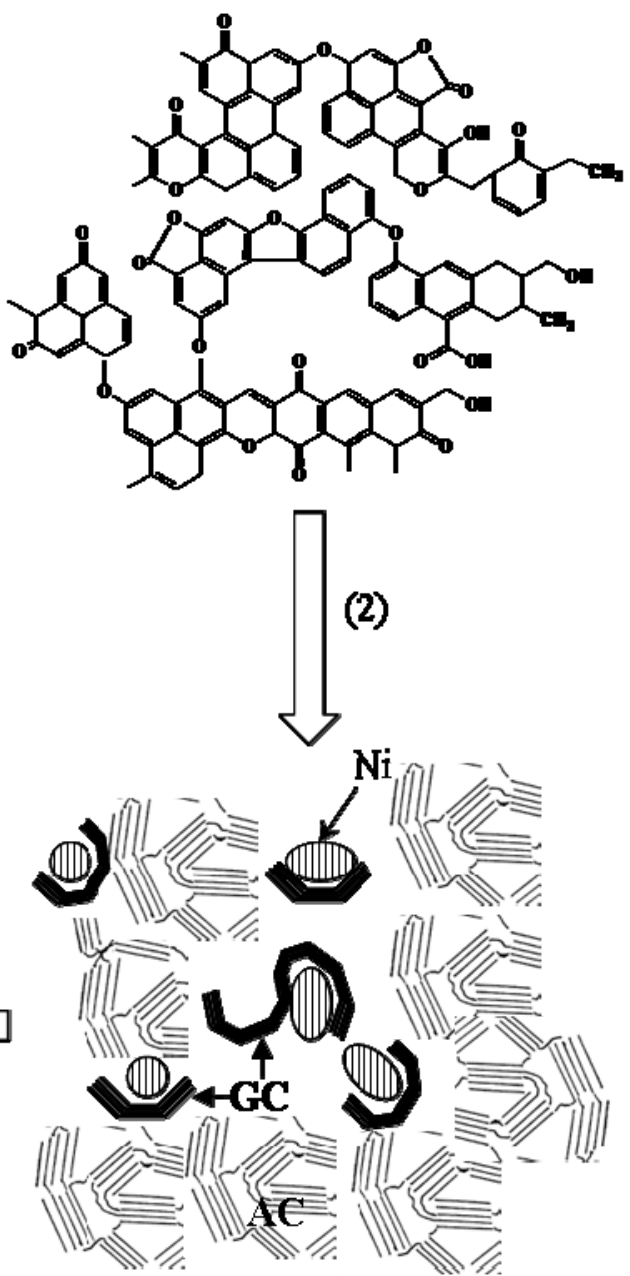

Amorphous carbon (AC)/Graphitic Carbon (GC)-Ni nanocomposite

Figure 6. Diagram of the overall synthesis process used to obtain graphitic carbon nanocoils from hydrothermally carbonized cellulose (i.e. hydrochar). The process consists of the following steps: (1) hydrothermal carbonization of a cellulose dispersion $\left(320 \mathrm{~g} \cdot \mathrm{L}^{-1}\right)$ at $250^{\circ} \mathrm{C}$ for $2 \mathrm{~h}$, (2) impregnation of the hydrochar with the graphitization catalyst (Ni) and carbonization at $900^{\circ} \mathrm{C}$ and (3) extraction of the GCNs by means of oxidation treatment with $\mathrm{KMnO}_{4}$. 

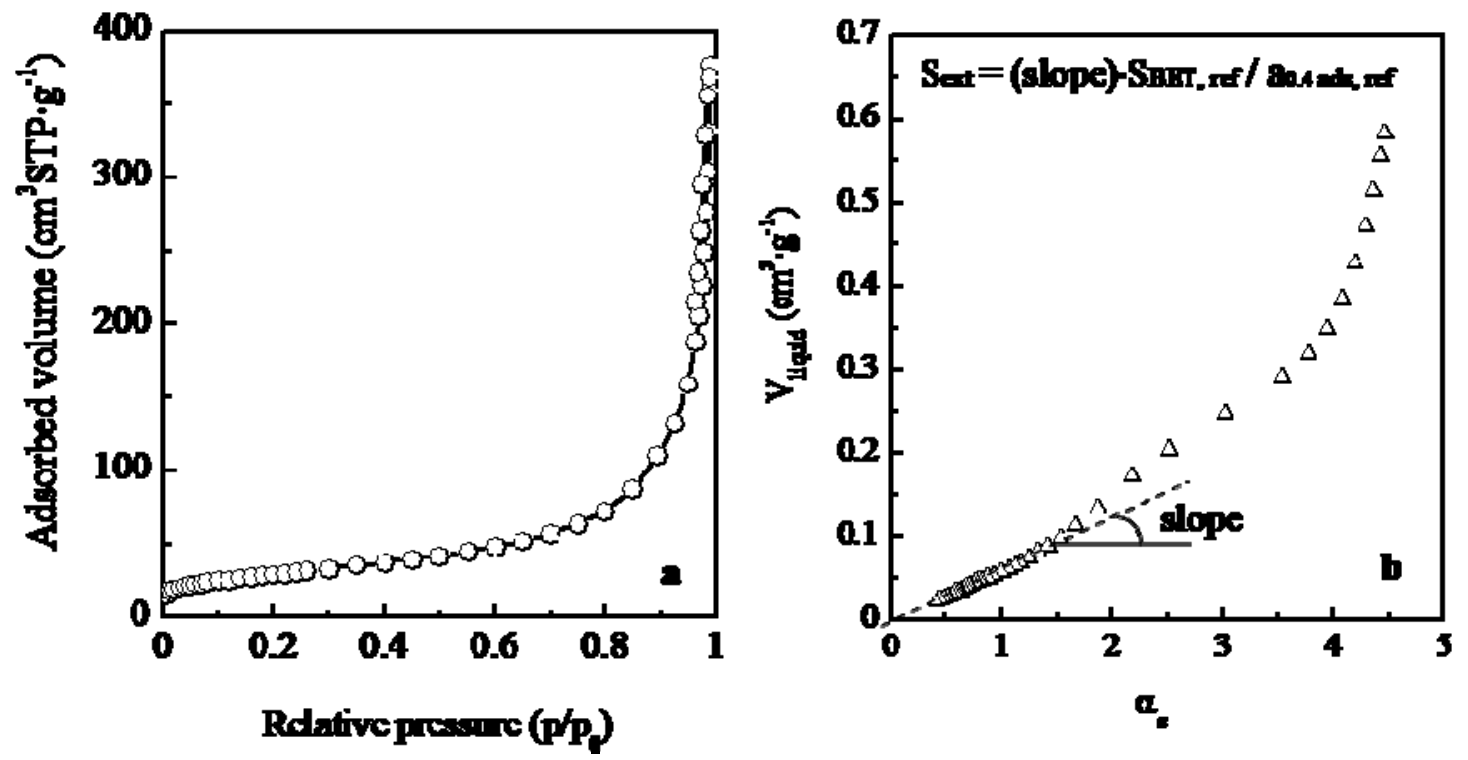

Figure 7. (a) Nitrogen sorption isotherm and (b) $\alpha_{\mathrm{s}}$-plot of the adsorption branch of the isotherm for the graphitic carbon nanostructures obtained from the cellulose-derived hydrochar sample. The method used for the calculation of the external surface area is illustrated in Figure (b). SBET,ref is the BET surface area of the material used as reference and $\alpha_{0.4}$ ads,ref is the amount of nitrogen $\left(\mathrm{cm}^{3} \mathrm{~N}_{2}\right.$ liquid. $\left.\mathrm{g}^{-1}\right)$ adsorbed by the reference solid at a relative pressure of 0.4 . For details see ref. [18]. 